\title{
Cost-benefit analysis of calcium and vitamin D supplements
}

\author{
Connie M. Weaver ${ }^{1} \cdot$ Heike A. Bischoff-Ferrari ${ }^{2,3,4} \cdot$ Christopher J. Shanahan $^{5}$
}

Received: 19 July 2018 / Accepted: 4 March 2019 / Published online: 30 April 2019

(C) The Author(s) 2019

\begin{abstract}
Summary If all adults with osteoporosis in the European Union (EU) and United States (US) used calcium and vitamin D supplements, it could prevent more than 500,000 fractures/year in the EU and more than 300,000/year in the US and save approximately $€ 5.7$ billion and US $\$ 3.3$ billion annually.

Purpose Evaluate the cost-effectiveness of calcium/vitamin D supplementation for preventing osteoporotic fractures.

Methods A cost-benefit analysis tool was used to estimate the net cost savings from reduced fracture-related hospital expenses if adults with osteoporosis in the EU and US used calcium/vitamin D supplements. A 14\% relative risk reduction of fracture with calcium/vitamin D supplementation from a recent systematic review and meta-analysis of randomized, controlled trials was used as the basis for the benefit estimate. Other model inputs were informed by epidemiologic, clinical, and cost data (2016-2017) obtained via the medical literature or public databases. Analyses estimated the total number of avoided fractures and associated cost savings with supplement use. Net cost benefit was calculated by subtracting the supplements' market costs from those savings.

Results The $>30$ million persons in the EU and nearly 11 million in US with osteoporosis experience about 3.9 million and 2.3 million fractures/year and have annual hospital costs exceeding $€ 50$ billion and $\$ 28$ billion. If all persons with osteoporosis used calcium and vitamin D supplements, there would be an estimated 544,687 fewer fractures/year in the EU and 323,566 fewer in the US, saving over $€ 6.9$ billion and $\$ 3.9$ billion; the net cost benefit would be $€ 5,710,277,330$ and $\$ 3,312,236,252$, respectively. Conclusions Calcium and vitamin D supplements are highly cost-effective, and expanded use could considerably reduce fractures and related costs. Although these analyses included individuals aged $\geq 50$ years, the observed effects are likely driven by benefits observed in those aged $\geq 65$ years.
\end{abstract}

Keywords Osteoporosis $\cdot$ Bone fracture $\cdot$ Calcium $\cdot$ Vitamin D $\cdot$ Costs and cost analysis $\cdot$ Cost savings

Electronic supplementary material The online version of this article (https://doi.org/10.1007/s11657-019-0589-y) contains supplementary material, which is available to authorized users.

Connie M. Weaver

weavercm@purdue.edu

1 Department of Nutrition Science, College of Health and Human Sciences, Purdue University, 700 W State Street, West Lafayette, IN 47907-2059, USA

2 Department of Geriatric Medicine and Aging Research, University Hospital and University of Zurich, Rämistrasse 100, 8091 Zurich, Switzerland

3 Centre on Aging and Mobility, University Hospital Zurich and Waid City Hospital, Zurich, Switzerland

4 University Clinic for Acute Geriatric Care, Waid City Hospital, Zurich, Switzerland

5 Frost \& Sullivan, 7550 Interstate 10 Frontage Rd \#400, San Antonio, TX 78229, USA

\section{Introduction}

According to the International Osteoporosis Foundation, osteoporosis is a worldwide epidemic [1]. Osteoporotic fractures are often the first sign of the disease [2], and frequently occur after a low-impact injury or fall, but vertebral fractures can also occur during routine activities in the absence of a fall or injury $[2,3]$. Fractures result in pain, deformity, height loss, impaired quality of life, restricted mobility, loss of independence, and, especially in the case of hip fractures, increased mortality $[2,3]$.

Recommended strategies for fracture prevention include, among other things, adequate consumption of calcium and vitamin D $[2,3]$. Mineralization of bone requires calcium, and dietary calcium absorption in the gut requires the presence of vitamin D [4]. Vitamin D also supports bone growth and remodeling by osteoblasts and osteoclasts [4]. For persons aged 51 years and older, United States (US) dietary guidelines 
recommend a daily calcium intake of $1200 \mathrm{mg}$ for women and $1000 \mathrm{mg}$ for men and a daily vitamin D intake of $600 \mathrm{mg}$ for both genders [5]. However, most North American osteoporosis guidelines recommend a vitamin $\mathrm{D}$ intake of at least 800 to $1000 \mathrm{IU} /$ day (maximum $4000 \mathrm{IU} /$ day) for adults aged 50 years and older $[2,3,6,7]$. European guidelines vary by country, but a daily intake of at least $1000 \mathrm{mg}$ of calcium, which includes dietary sources of calcium, and 400 to $800 \mathrm{IU}$ of vitamin D is generally recommended $[8,9]$.

Unfortunately, calcium and especially vitamin D are both underconsumed dietary nutrients [5], and inadequacies in these nutrients are a key preventable risk factor for osteoporosis [10]. Among persons who rely on food alone for their vitamin and mineral intake, about $38 \%$ consume inadequate levels of calcium and about $93 \%$ consume inadequate levels of vitamin D [11]. Vitamin D is also produced in the skin in response to sunlight, but sunshine exposure may be limited by climate or sunscreen use [5]. About 58\% of persons in Europe have serum 25-hydroxyvitamin D levels $<30 \mathrm{ng} / \mathrm{mL}$ [12].

It remains controversial as to whether increasing dietary calcium intake results in clinically meaningful fracture reduction [13-15]. Also, calcium supplementation alone does not reduce fracture risk compared with placebo [16]. However, calcium and vitamin D supplementation is associated with a $14 \%$ reduction in overall risk of fractures and a 39\% reduction in risk of hip fractures in generally healthy adults, according to a recent metaanalysis [4]. Most professional guidelines from North America and the European Union (EU) support the use of supplements to maintain adequate calcium and vitamin $\mathrm{D}$ intake $[2,3,6,7,9]$.

Expanded use of combined calcium and vitamin D supplements has the potential to lower the risk of fracture. The financial impact of such prevention efforts is unclear, however, since the supplements have an associated cost and would need to be used by a large number of people to prevent one fracture. This analysis evaluated the net cost savings that could be derived from reduced hospital expenses for bone fracture if all adults aged 50 and older with osteoporosis in the EU and the US used calcium and vitamin D supplements, assuming a $14 \%$ reduction of total fracture risk [4]. We hypothesized that, despite the costs of the supplements, savings would be derived from a reduction in fractures.

\section{Methods}

\section{Target populations}

This analysis calculated fracture risk reduction and cost savings from calcium and vitamin D supplements in target populations consisting of adults aged 50 and older with osteoporosis in the EU and US. In addition, analyses were performed to evaluate risk reduction and cost savings in subgroups of those populations by age (50-59 years, 60-69 years, 70-
79 years, and $>80$ years) and gender. All analyses were performed by Frost \& Sullivan (San Antonio, TX, USA).

\section{Identification of fracture risk and related costs}

We derived overall EU and US population data, as well as population data for individual countries and states, from Eurostat [17], the US Census Bureau [18], and the Kaiser Family Foundation [19]; data were adjusted to align with the 10 -year age bands of the target populations and were also sorted by gender. We modeled the current prevalence of osteoporosis by applying osteoporosis prevalence data from Hernlund et al. [8] for the EU and Wright et al. [20] for the US to current total population figures. Gaps in information, including missing EU countries, were approximated using similar findings from the nearest and most similar country with complete information.

We modeled the number of osteoporosis-attributed fractures using reported annual fracture incidence rates derived from Kanis et al. [21] and Johnell et al. [22] for the EU and Burge et al. [23] for the US. Our estimates are conservative in nature because the data from Kanis et al. [21] are for hip fractures only. As US state-level fracture rates were not available, we first applied the osteoporosis prevalence rates by state from Wright et al. [20] to distribute expected osteoporosisattributed bone fractures. Relative incidence rates of osteoporosis-attributed fractures for each EU country and US state were then applied to current population data to obtain estimated current osteoporosis-attributed bone fracture rates. Future survey research is required to verify the latest osteoporosis fracture rates. The incidence of fracture $(F)$ in each target population was then calculated as the number of fractures per year/number of people with osteoporosis.

We modeled the estimated per-person and total annual costs of an osteoporosis-attributed bone fracture using reported costs from Hernlund et al. [8] for the EU and Weycker et al. [24] and Burge et al. [23] for the US. Since the study by Kanis et al. reported costs for base year 2010, we scaled these figures upward to account for inflation, assuming a $2 \%$ annual growth in per-fracture cost from 2010 to 2016. Purchasing power parity (PPP) per EU country and US state was used to further control and adjust for relative healthcare costs between countries and states. We relied on the data from Burge et al. [23] to segment costs by gender, age, and US state and adjusted for target population growth. We calculated the cost equivalent for each of the estimated 2.3 million total fractures in 2016 by multiplying the average cost of fracture (US $\$ 12,197$ ) times the PPP of each US state and a cumulative inflation rate of 43.7\% between 2005 and 2016 (consistent with a conservative estimate of about $3.6 \%$ annual growth of the US healthcare spending [25]). Future survey research is required to verify the estimated annual cost of an osteoporosis-attributed bone fracture. 


\section{Determination of expected impact of calcium/vitamin D supplements on fracture risk}

A search of the medical literature identified a recent, comprehensive meta-analysis of 7 randomized, controlled trials [26-32] of calcium (500-1200 mg/day) plus vitamin D (400$800 \mathrm{IU} /$ day) supplementation for fracture prevention in generally healthy community-dwelling and institutionalized adults conducted by the National Osteoporosis Foundation (Table 1) [4]. The final analysis, published in a correction, reported a summary relative risk estimate of 0.86 (95\% CI, 0.75-0.98), indicating that supplementation would reduce the overall population risk of osteoporotic fracture by $14 \%$ [4]. Thus, the current analysis utilized a relative risk reduction (RRR) for total fracture of 0.14 with calcium and vitamin D supplementation.

The RRR (0.14) was used to calculate the absolute risk reduction realizable for each target population by multiplying it by the target population's incidence of an osteoporosisattributed bone fracture $(F)$. Number needed to treat (NNT) - i.e., the total number of people who would have to be treated with the supplements to achieve one avoided fracture event-was calculated as $1 /(F-[F \cdot R R R])$. The number of avoided fractures $\left(N^{*}\right)$ was calculated as the number of people in the target population with osteoporosis multiplied by the absolute risk reduction or the inverse of NNT.

\section{Calculation of net realizable healthcare cost savings}

A previously published cost-benefit analysis tool developed by researchers at Frost \& Sullivan was used for this analysis [33]. The following equation was used to calculate total potential savings $(S)$ from reduced hospital services following osteoporosisattributed fracture that would be realizable if the entire target population used a calcium and vitamin D supplement: $S=h$. $N *$ where $h$ is the expected per-person cost of an osteoporosisattributed bone fracture for a member of the target population (Pop) derived as described above.

It is also necessary to take into account the cost of the calcium and vitamin $\mathrm{D}$ supplement. Therefore, the net cost benefits $(B)$ that could be realized from avoided osteoporosis-attributed bone fractures were calculated as $B=S-C=S-(P o p \cdot d)$, where cost savings $S$ is calculated as described above and the total population cost $(C)$ of calcium and vitamin D supplementation is represented by $C=P o p \cdot d$ where Pop is the total number of at-risk people in the target population and $d$ is the expected annual per-person cost for a 1000-mg/day calcium and 600-IU/ day vitamin D supplement regimen. In order to have a reasonable estimate of savings, we based supplement costs on calcium and vitamin $\mathrm{D}$ doses at the relatively higher end of the usual dose ranges studied in the meta-analysis on which the RRR was based; these regimen levels represent mid to high doses of supplements typically available to consumers from the marketplace. A vitamin D dose of $600 \mathrm{IU}(15 \mu \mathrm{g})$ per day has also been established by the European Food Safety Authority as adequate intake for adults to achieve a target serum 25-hydroxyvitamin D concentration of $50 \mathrm{nmol} / \mathrm{L}$ [34]. Supplement cost $(d)$, which represents the average cost across a wide range of available supplements, was determined based on market analysis performed by Frost \& Sullivan (unpublished data, 2017).

Note that the entire target population must take the given regimen in order for the total number of avoided events to be realized. Thus, $B$ represents the net monetary benefits that use of calcium and vitamin D supplements can yield through hospital cost reduction with $100 \%$ utilization of supplements by the target population.

\section{Results}

\section{Osteoporosis, fractures, and associated hospital costs}

In the EU, an estimated 30,485,309 persons aged 50 years and older have osteoporosis, representing nearly $15 \%$ of persons in that age range (Table 2). In the US, an estimated 10,887,910 persons aged 50 years and older have osteoporosis, representing about $10 \%$ of the US population of that age (Table 2). Women account for about $80 \%$ of those with osteoporosis in both the EU and the US. Osteoporosis rates increase with age in both regions and are about $7 \%, 12 \%$, and $24 \%$ among persons in their 50 s, $60 \mathrm{~s}$, and $70 \mathrm{~s}$ in the EU and $5 \%, 8 \%$, and $16 \%$ in those age groups in the US, respectively. In both regions, a little more than a quarter of those aged over 80 years have osteoporosis.

The estimated annual fracture incidence among persons with osteoporosis is $12.9 \%$ in the EU and $21.4 \%$ in the US, which translates to about 3.9 million fractures per year in Europe and 2.3 million per year in the US (Table 2), respectively. Although men have a lower risk of osteoporosis, those with osteoporosis have a higher risk of fracture compared with women with osteoporosis: $21.7 \%$ year vs $10.6 \%$ year in the EU and $31.9 \%$ vs $18.9 \%$ in the US. Among persons with osteoporosis, fracture rates appear to be similar across age groups, at about $12-13 \%$ in the EU and $21-22 \%$ in the US.

In the EU, osteoporosis-related fractures result in hospital costs of about $€ 12,772$ per person and over $€ 50$ billion annually (Table 2), with women accounting for $66 \%$ of cases. Hospital costs for osteoporosis-related fractures in the US are about $\$ 12,197$ per person and over $\$ 28$ billion annually (Table 2), with women accounting for about $71 \%$ of costs. Those aged $\geq 80$ years account for about $26 \%$ of the total osteoporotic fracture-related hospital costs in the EU and $29 \%$ in the US.

\section{Fracture reduction with calcium and vitamin D supplementation}

Fifty-six people in Europe, or 34 people in the US, would need to be treated with calcium and vitamin D supplements to prevent 


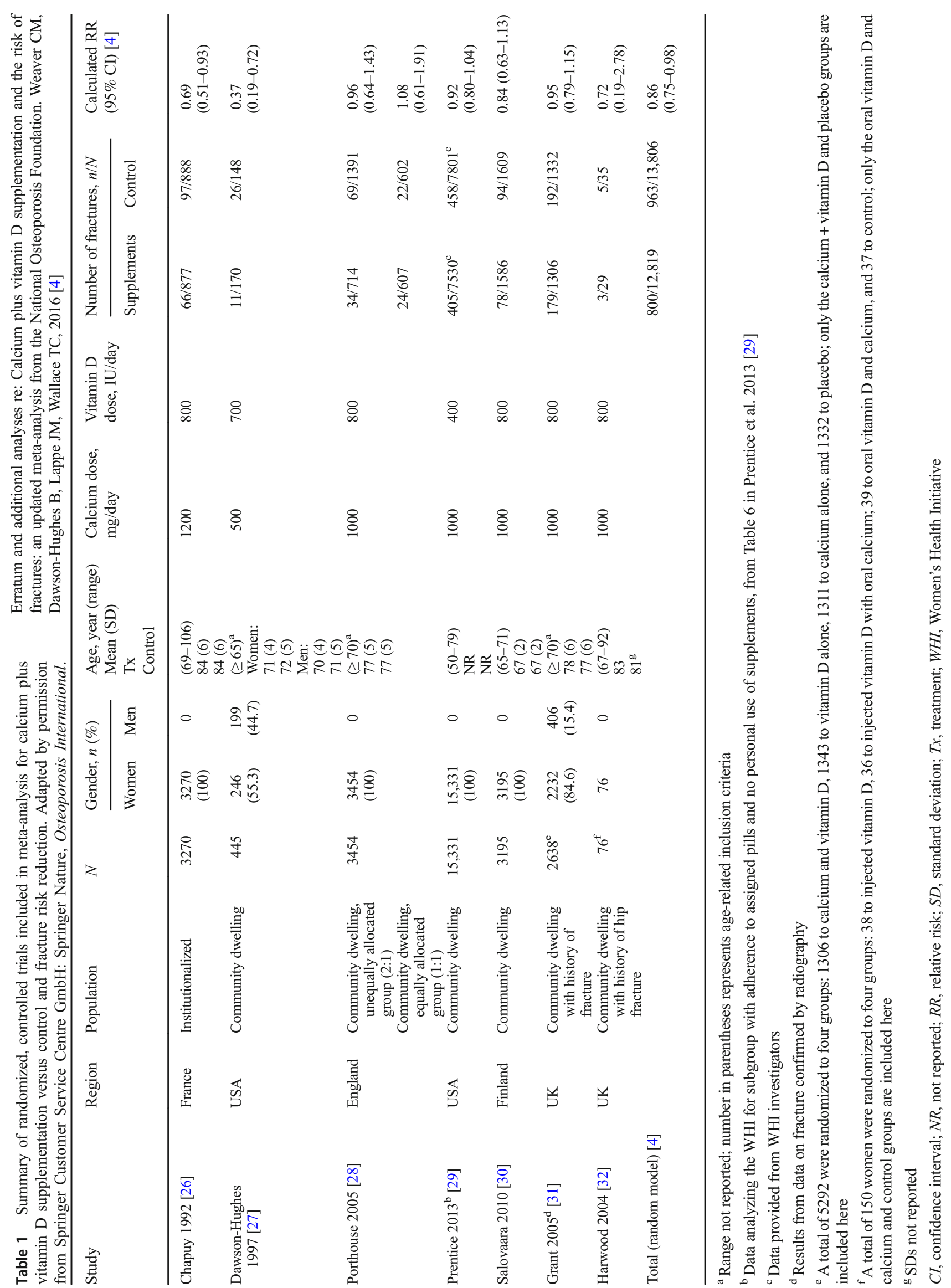




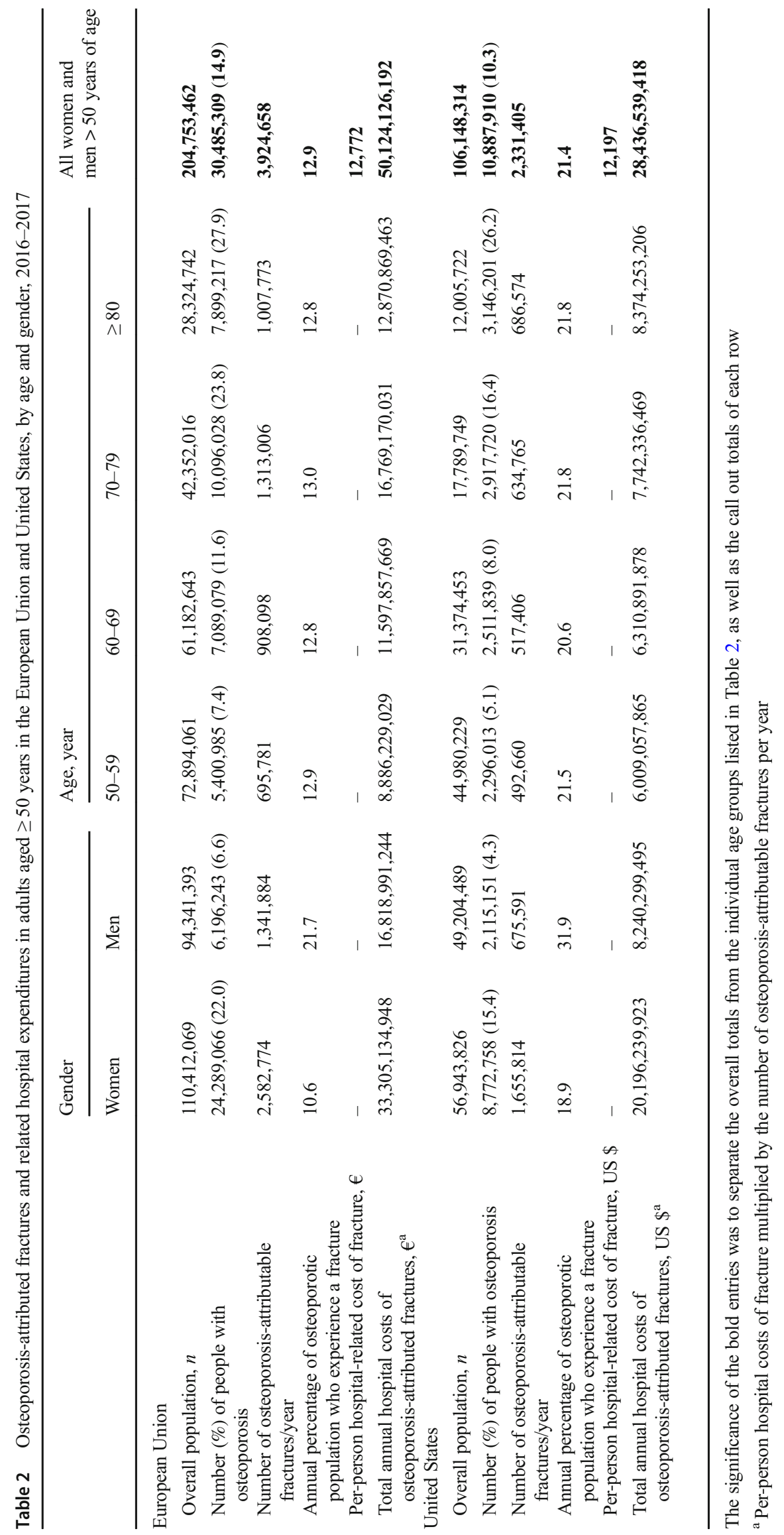


one fracture in each of those target populations. Absolute risk reduction would be $1.8 \%$ in Europe and $3.0 \%$ in the US. If everyone aged 50 years and older took calcium and vitamin D supplements, an estimated 544,687 fractures would be prevented annually in the EU (Fig. 1a) and 323,566 would be prevented annually in the US (Fig. 1b). The number of avoided fractures would be higher in women than in men and would be highest among those in their 70s in the EU and in those $\geq 80$ years old in the US compared with the other age groups (Fig. 1a and b).

\section{Cost savings with calcium and vitamin D supplementation}

The reduction in fractures with calcium and vitamin D supplementation would save nearly $€ 7$ billion in the EU and nearly $\$ 4$ billion in the US annually (Table 3). Factoring in the cost of the supplements, this would result in a net cost benefit of approximately $€ 5.7$ billion (Fig. 2a) and $\$ 3.3$ billion (Fig. 2b) per year, respectively. The EU would save $€ 5.58$ in hospital costs for each $€ 1$ spent on calcium and vitamin D supplements, and the US would save $\$ 6.22$ per $\$ 1$ spent (Table 3). Breakdowns of the net cost/savings ratio by EU country and US state are provided in the Electronic Supplemental Materials (Online Resource 1), which also contain a breakdown of the overall cost analysis by EU country (Online Resource 2) and US state (Online Resource 3). Additionally, data describing osteoporosis-attributed fractures and related hospital expenditures in adults aged $\geq 50$ years in the EU by age and gender are included in Online Resource 4; these data were not available for the US.

Fracture reductions in women would account for over $€ 3.6$ billion $(\sim 64 \%)$ of the cost savings in the EU (Fig. 3a) and nearly $\$ 2.3$ billion $(\sim 69 \%)$ of the cost savings in the US (Fig. $3 b)$. Cost savings associated with calcium and vitamin D supplementation increase with age in both populations up to age 80 and then begin to plateau or decline due to diminishing population levels for those in the age $\geq 80$ cohort (Fig. 3a and b).
Fig. 1 Estimated number of fractures avoided annually, by gender and age, with $100 \%$ use of calcium and vitamin $\mathrm{D}$ supplementation by adults aged $\geq 50$ years in a the European Union and $\mathbf{b}$ the United States
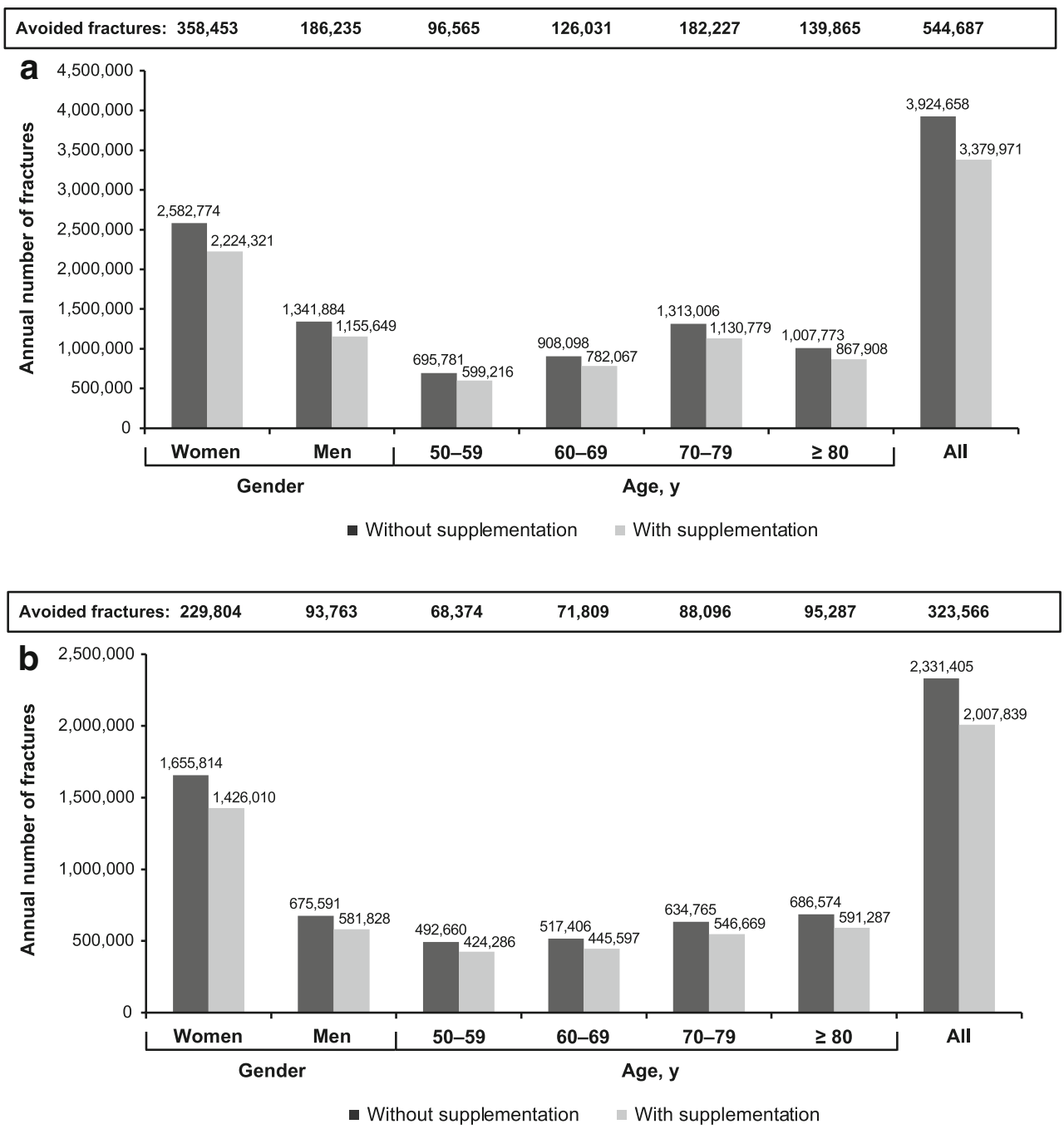
Table 3 Calcium and vitamin D supplementation cost benefit analysis, 2016-2017

\begin{tabular}{lll}
\hline & European Union, $€$ & United States, US \$ \\
\hline Cost savings (avoided hospital costs for osteoporosis-attributable fractures) & \\
Total annual savings (S) & $6,956,520,691$ & $3,946,589,993$ \\
Per-person annual savings & 228.19 & 362.47 \\
Costs of calcium and vitamin D supplements & & \\
Total annual cost (C) per target population & $1,246,243,361$ & $634,353,741$ \\
Daily per-person cost & 0.11 & 0.16 \\
Annual per-person cost & 40.88 & 58.44 \\
Net cost benefits & & \\
Annual net cost benefit (S - C) & $5,710,277,330$ & $3,312,236,252$ \\
Net benefit/cost ratio (S/C) & 5.58 & 6.22 \\
\hline
\end{tabular}

\section{Discussion}

Dietary supplements are a simple, noninvasive measure with potential preventive health benefits. The current analysis supports our hypothesis and suggests that expanding the use of these supplements to $100 \%$ of adults aged $\geq 50$ years could reduce the annual number of fractures by 544,687 in the EU and 323,566 in the US, resulting in a net cost benefit of over
Fig. 2 Cost analysis: net healthcare cost savings in terms of reduced hospital costs for osteoporosis-attributable fracture if all persons aged $\geq 50$ years used calcium and vitamin $\mathrm{D}$ supplements in a the European Union and $\mathbf{b}$ the United States, 2016-2017
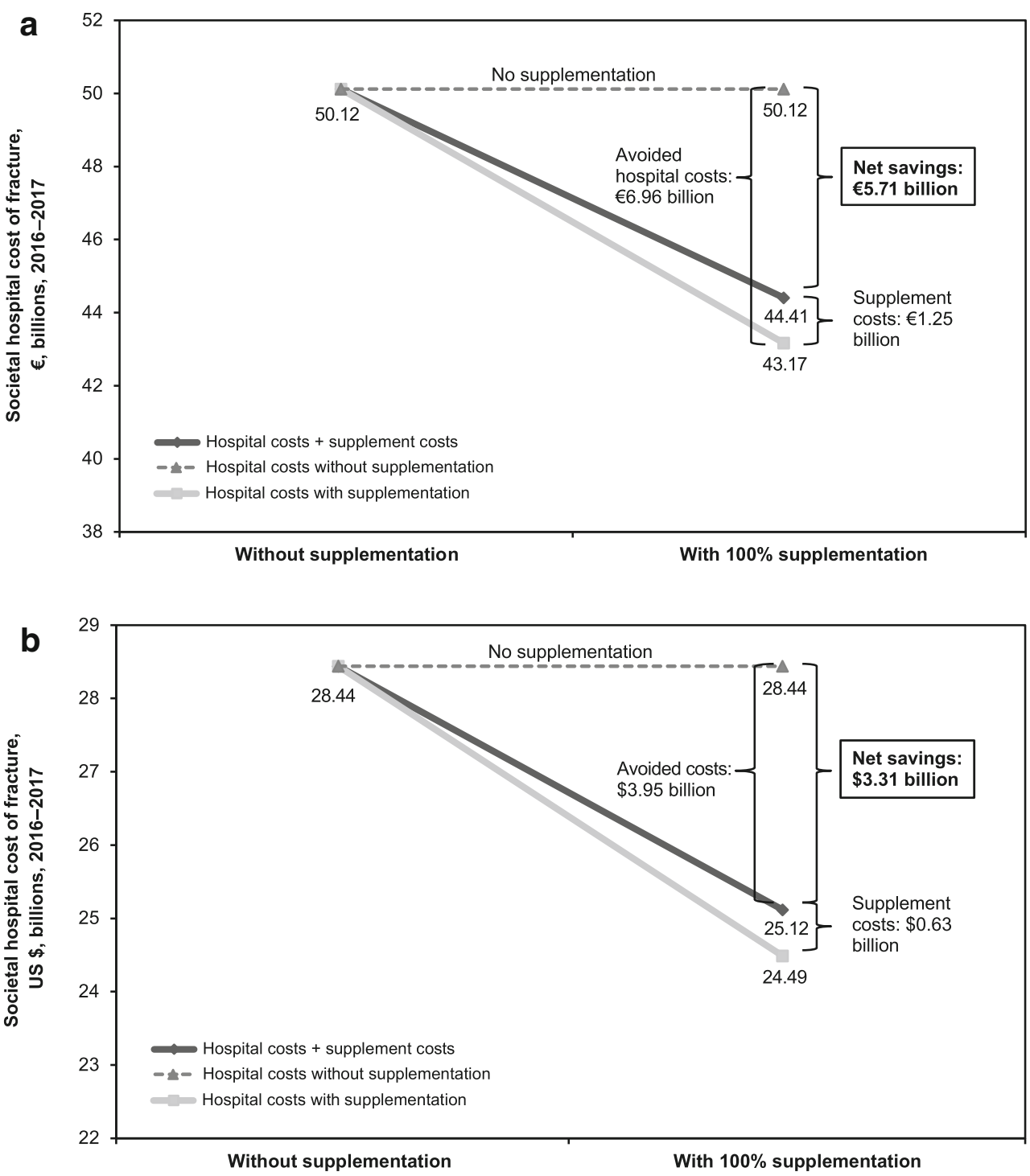
Fig. 3 Net cost benefits, by gender and age, with $100 \%$ use of calcium and vitamin D supplementation by adults aged $\geq 50$ years in a the European Union and $\mathbf{b}$ the United States
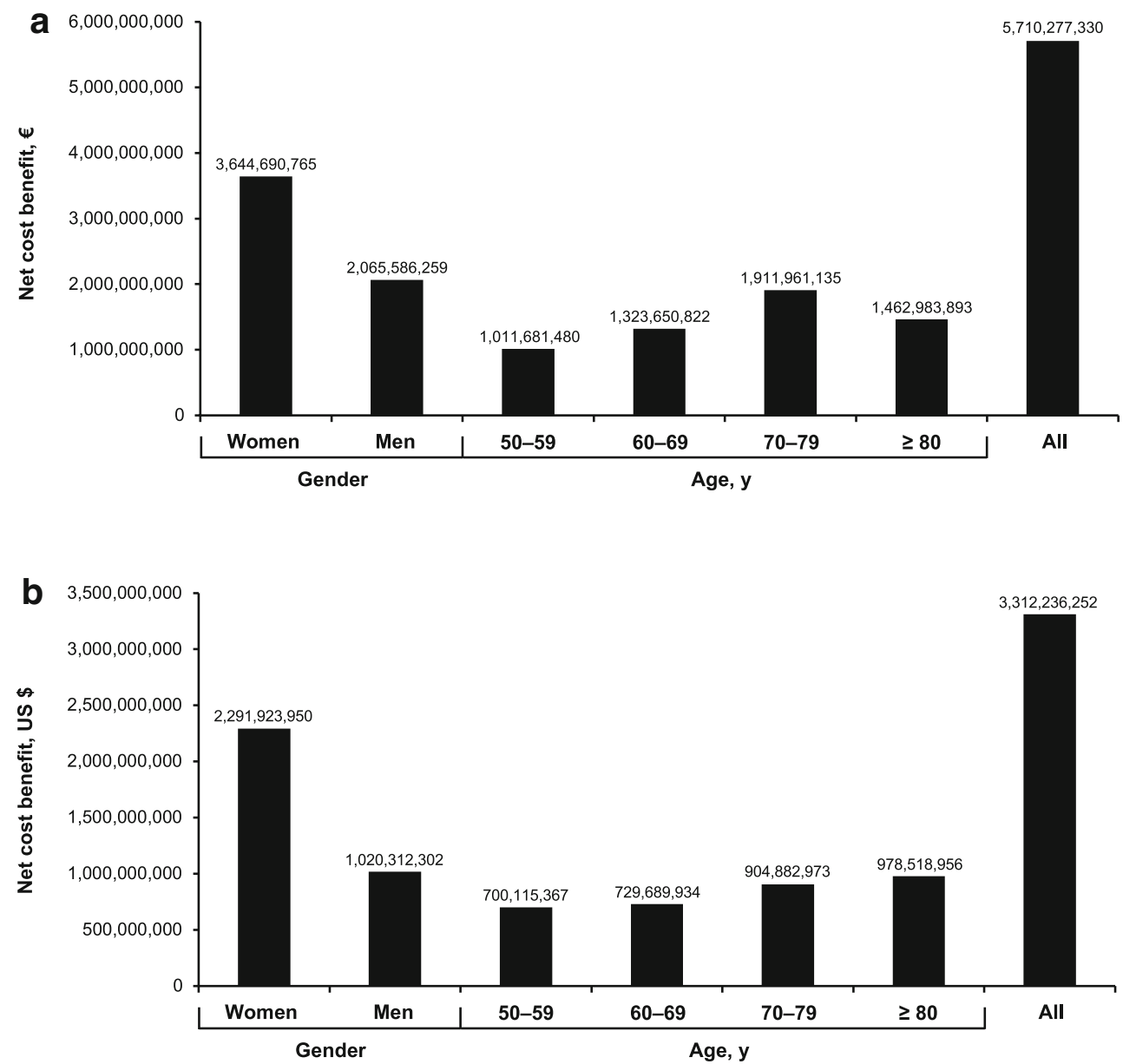

$€ 5.71$ billion and $\$ 3.31$ billion, respectively, in avoided fracture-related hospital costs. Thus, it can be concluded that calcium and vitamin D supplements are highly cost-effective. However, it is important to note that the benefits observed in the overall population may in part be driven by greater reductions in the older populations, in particular in those aged $\geq 65$ years, who comprise the majority of the population used to calculate the risk reduction, have higher risks for osteoporosis-related fractures, and may be more detrimentally affected by vitamin $\mathrm{D}$ deficiencies. As noted above, the benefits increased with age in these analyses. These findings may assist persons with osteoporosis, their healthcare providers, government and private insurance companies, and employers in making decisions or recommendations that could help minimize current and future fracture risks and related costs.

Fracture reduction and cost savings were predicted for both genders and across all age groups 50 years and older; however, increased use of calcium and vitamin $\mathrm{D}$ supplementation by women, particularly older women, has the potential to produce the greatest benefits with regard to fracture reduction and cost savings. One caveat is that our analysis applied a $14 \%$ reduction in fracture risk with supplementation across all age groups and both genders. The $14 \%$ total fracture reduction was derived from the recent meta-analysis by Weaver and colleagues [4]; most of the individuals enrolled in the studies included in that metaanalysis were 65 years of age and older, and only 1 study contributed data from women aged 50 years and older (Table 1) [29]. Therefore, future cost-benefit analyses in this area may benefit from additional analyses that control for age and determine the benefits for the different age groups evaluated. Also, the studies included in the Weaver et al. meta-analysis included fewer men, and the authors did not attempt to determine whether RRR varies by age or gender. Although men have a lower baseline risk of fracture [35], there is evidence in other studies and meta-analyses that they derive a benefit from calcium and vitamin D supplementation similar to women $[31,36]$. Further studies are needed to confirm whether persons in their 50s derive the same benefits from calcium and vitamin D supplementation in terms of fracture reduction as older persons; it is possible that by applying the same RRR across all age groups, we have overestimated benefits in this younger age group and also underestimated benefits in the oldest groups. In addition, it should be noted that the original meta-analysis evaluated fracture reduction with calcium and vitamin D supplements in generally healthy adults, whereas our cost analysis is limited to persons with osteoporosis, who represent a high-risk subgroup. 
A previous cost analysis predicted that costs of osteoporosis-related fracture in the US would grow from $\$ 16.9$ billion in 2005 to $\$ 25.3$ billion in 2025 [23]. Similarly, another previous cost analysis estimated that overall costs of osteoporotic fracture in Europe would increase from approximately $€ 37.4$ billion in 2010 to nearly $€ 46.8$ billion by 2025 [8]. Using their initial costs as a base and adjusting for price inflation and PPP between US states and EU countries, we estimated that hospital costs related to osteoporotic fractures have already exceeded \$28.4 billion in 2016-2017 in the US and $€ 50.1$ billion in Europe. Future survey research is required to verify the estimated annual cost of an osteoporosis-attributed bone fracture. Another analysis predicted that adequate dairy intake containing 1000 to $1500 \mathrm{mg} /$ day calcium could provide a $20 \%$ reduction in fracture risk and cost savings totaling $\$ 3.5$ billion per year [37]; however, a subsequent meta-analysis found no overall association between dairy consumption and hip fracture risk [15].

It should be noted that the 14\% RRR may be a conservative estimate of fracture reduction with calcium and vitamin D supplements. An earlier meta-analysis found vitamin D supplements at doses of 482-770 IU/day with or without calcium supplements were associated with a $20 \%$ reduction in all nonvertebral fractures and an $18 \%$ reduction in hip fracture [36]. In addition, the meta-analysis we used to derive the RRR included studies of supplements containing 500 $1200 \mathrm{mg} /$ day of calcium and 400-800 IU/day of vitamin D [4]. On the other hand, we may have overestimated a benefit of calcium in combination with vitamin $\mathrm{D}$ given the most recent meta-analysis by Zhao and colleagues [38], in which the authors found only a $10 \%$ nonsignificant reduction in total fracture risk with these supplements (risk ratio $=0.90$; 95\% CI, 0.78-1.04). However, 1 of the 8 trials included in that meta-analysis had a follow-up of less than 12 months, which is too short for fracture benefits to be expected; half of the studies had no control intervention; and the focus was on individuals aged $\geq 50$ years, which may have lessened the impact that may have been observed in an older population. These limitations may have prevented the authors from documenting a benefit. Further, the most recent metaanalyses by Bolland and colleagues, which concluded there was no benefit of vitamin D on fracture risk, excluded all trials of vitamin D plus calcium [39, 40].

Our analysis was based on costs of supplements containing $1000 \mathrm{mg} /$ day calcium and $600 \mathrm{IU} /$ day vitamin D. Additional analyses to determine the exact impact of calcium and vitamin D supplement dose on the relative risk of fracture and related costs should be considered for future investigation, especially since benefits of vitamin D supplementation have been found to be dose related [36].

There are a number of challenges inherent to studies of nutritional interventions. For example, control groups are not truly untreated since they still have some level of intake from diet, as well as production of vitamin D from sun exposure, and possible intake of other dietary supplements containing these nutrients. The underlying meta-analysis by Weaver and colleagues [4] and the current cost analysis were not adjusted for baseline dietary or supplemental calcium and vitamin D intake. Data from the National Health and Nutrition Examination Survey (NHANES) show that usual intake among US adults age 19 years and older is $1061 \pm 15 \mathrm{mg}$ calcium from food alone versus $1277 \pm 1 \mathrm{mg}$ from food and supplements among supplement users; usual vitamin D intake is $5.17 \pm 0.16 \mu \mathrm{g}$ from food alone versus $17.1 \pm 0.3 \mu \mathrm{g}$ from food and supplements [11]. It can be seen from these NHANES data that supplements often help bring calcium and vitamin $\mathrm{D}$ intake closer to recommended levels.

Thereby, we note that the assumption of the current model that each target population shifts from zero to $100 \%$ usage of calcium and vitamin D supplements may overestimate the expected cost-benefit, as we do not take into account that each target population already includes some proportion of persons who are regular users of calcium and vitamin D supplements. Such individuals have therefore already realized the potential risk- and cost-reducing benefits of these supplements. A 2017 survey of 2001 US adults (age 18 years and older) by the Council for Responsible Nutrition found that $20 \%$ were using calcium supplements and $28 \%$ were using vitamin D supplements [41]. Thus, as a rough estimate, assuming that the $20 \%$ of calcium supplement users were all also vitamin D supplement users and that a similar proportion of the subgroup of persons aged 50 years and older were regular users, then a conservative estimate would be that at least $80 \%$ of persons in this age group have not yet realized the benefits of regular use. This still amounts to an unrealized potential reduction of 258,852 fractures and $\$ 2,649,789,001$ net cost benefit in the US. Future investigations should include sensitivity analyses using different estimates of risk reduction and taking into account the impact of adherence and personal supplement use on both fracture risk reduction and supplement cost.

This cost model is based on 100\% adherence, which represents an ideal scenario not typical of real-world use. Nonetheless, this model provides information as to maximum potential benefit from calcium and vitamin D supplements in the target populations, with the understanding that actual net benefits would be lower with lower rates of supplement uptake or less than $100 \%$ adherence among supplement users.

Currently, there is some controversy as to whether metaanalyses of calcium and vitamin D supplements should include all subjects (intent-to-treat population) or only those who were adherent during clinical trials [4, 29, 42]. Data from the Women's Health Initiative (WHI) studies have been analyzed using multiple approaches: an intent-to-treat approach that evaluated the total population irrespective of adherence, a subgroup analysis that included only those subjects who were not taking personal supplements at baseline, and a per- 
protocol analysis that included only subjects who were not using supplements at baseline and who then adhered to the assigned supplement [29]. Not surprisingly, since treatments can only work if they are taken, the third approach provided the most compelling support for fracture reduction with calcium and vitamin D supplementation [29]. The meta-analysis used to determine RRR for the current cost analysis included the latter of these three groups from the WHI, and sensitivity analyses conducted using the other WHI analysis populations produced fairly similar results [4]. Data on fracture reduction in the subgroup of adherent participants were lacking in other studies included in the meta-analysis; however, it should be noted that the $14 \%$ reduction in fracture was seen even with less than $100 \%$ adherence in all of the trials [4]. In fact, reported adherence rates were as low as $55 \%$ to $63 \%$ in some of the included trials $[28,31]$. Thus, the RRR used in this analysis is likely a conservative estimate of the benefit of supplements, given that those in the placebo group still have some baseline exposure to calcium and vitamin D and those in the treated group were not fully adherent.

The RRR for fracture in this analysis was derived from a meta-analysis in healthy community-dwelling and institutionalized adults and applied to a subgroup of such persons with osteoporosis; actual RRR may be higher or lower in this subgroup. In addition, since a majority of fragility fractures occur in persons with bone mineral density in the osteopenic range [43], additional cost analyses are needed to identify potential cost savings if calcium and vitamin D supplementation was expanded to include those with osteopenia, especially at elevated risk based on Fracture Risk Assessment Tool thresholds (e.g., $\geq 20 \% 10$-year probability for major osteoporotic fracture or $\geq 3 \% 10$-year probability of hip fracture in the US) [44].

The current analysis measures total benefits and does not necessarily predict fracture risk and savings for individual persons whose potential benefits vary with their specific risk of osteoporosis-related fracture. Individual fracture risk is dependent on a variety of factors such as age, race, gender, body mass index, bone mineral density, previous fracture history, health conditions (e.g., rheumatoid arthritis, hyperthyroidism, chronic liver disease), concurrent medications (e.g., glucocorticoids), and alcohol and tobacco use [44]. Evaluating the effects of calcium and vitamin D supplements on fracture risk would benefit from also evaluating their effects on bone quality. In addition, cost benefits might differ if looked at from either a patient or a payer perspective instead of a societal perspective. In real-world settings, actual costs are borne by a combination of insurers and patients. While insurers probably cover a majority of the hospital-based costs associated with fracture, patients likely bear the out-of-pocket costs of over-the-counter supplements, although in Europe, individual countries (e.g., Switzerland and Germany) reimburse the costs via health insurance claims for patients with established osteoporosis. Theoretically, if the out-of-pocket costs of the supplements were shifted to insurers, the removal of a cost barrier for patients could potentially lead to increased supplement use and associated decreases in fractures that would still result in cost savings for insurers based on the current analysis.

Only direct costs of hospitalization related to fracture were included in this cost-benefit analysis. Thus, the analysis does not take into account impact on other medical expenses (e.g., long-term care) or indirect costs (e.g., absenteeism and loss of productivity) related to fracture, nor does it take into account the impact to society of potential lost tax revenue. Some of those costs can be extensive (e.g., the cost of long-term care for disability from osteoporosis was $€ 10.7$ billion in Europe in 2010 [1]). Therefore, additional cost benefits beyond those measured in this analysis are potentially realized if fractures are reduced through expanded supplementation use.

As global populations continue to age, a considerable increase in osteoporosis prevalence is anticipated [1]. In fact, the number of individuals over the age of 50 years worldwide who are at high risk of osteoporotic fracture is expected to rise by about $30 \%$ in Europe and more than 50\% in North America from 2010 to 2040 [45]. The current analysis suggests that expanding combined use of calcium and vitamin supplements among adults in this age group has the potential to reduce the risk of fractures and substantially reduce hospital costs for osteoporosis-attributable fractures. Potential cost savings based on 2016-2017 data amount to over €5.71 billion and nearly $\$ 3.31$ billion per year in Europe and the US, respectively.

Acknowledgments This analysis was sponsored by Pfizer Consumer Healthcare. Medical writing support was provided by Lauren Cerruto; Dennis Stancavish, MA; and Diane M. Sloan, PharmD, of Peloton Advantage, LLC, and was also funded by Pfizer.

Funding This analysis was sponsored by Pfizer Consumer Healthcare.

\section{Compliance with ethical standards}

Conflict of interest Connie M. Weaver, $\mathrm{PhD}$, has served as a scientific advisor for International Life Sciences Institute, Pfizer, Pharmavite, and YINI and has received grants from ISI North America, DMI, and Tate \& Lyle.

Heike A. Bischoff-Ferrari, DrPH, receives independent investigatorinitiated funding from the European Commission within the Framework 7 Research Program (DO-HEALTH study: ClinicalTrials.gov identifier, NCT01745263), the Swiss National Foundations (T\&D trial: ClinicalTrials.gov identifier, NCT02419105), the Velux Foundations (ClinicalTrials.gov identifier, NCT01017354), and DSM Nutritional Products (ClinicalTrials.gov identifier, NCT02527668). She has also received honoraria for speaking at symposia from DSM, Mylan, Nestlé, Roche Diagnostics, Sandoz, and Sanofi; is a consultant for Nestlé, Pfizer, Sandoz, and Sanofi; and holds a position on the board of directors for the Swiss Association Against Osteoporosis.

Christopher J. Shanahan, Global Director-Agriculture \& Nutrition, Frost \& Sullivan, received funding from Pfizer Consumer Healthcare for performing the literature search and cost analysis. 
Statement of human and animal rights This article does not contain any studies with human participants or animals performed by any of the authors.

Open Access This article is distributed under the terms of the Creative Commons Attribution 4.0 International License (http:// creativecommons.org/licenses/by/4.0/), which permits unrestricted use, distribution, and reproduction in any medium, provided you give appropriate credit to the original author(s) and the source, provide a link to the Creative Commons license, and indicate if changes were made.

\section{References}

1. (2014) The global burden of osteoporosis: a factsheet. International Osteoporosis Foundation. https://www.iofbonehealth.org/sites/ default/files/media/PDFs/Fact\%20Sheets/2014-factsheetosteoporosis-A4.pdf. Accessed February 12, 2019

2. (2010) NAMS continuing medical education activity: management of osteoporosis in postmenopausal women: 2010 position statement of the North American Menopause Society. Menopause 17:23-24. doi: https://doi.org/10.1097/gme.0b013e3181cdd4a7

3. Camacho PM, Petak SM, Binkley N, Clarke BL, Harris ST, Hurley DL, Kleerekoper M, Lewiecki EM, Miller PD, Narula HS, PessahPollack R, Tangpricha V, Wimalawansa SJ, Watts NB (2016) American Association of Clinical Endocrinologists and American College of Endocrinology clinical practice guidelines for the diagnosis and treatment of postmenopausal osteoporosis. Endocr Pract 22:1-42. https://doi.org/10.4158/ep161435.gl

4. Weaver CM, Alexander DD, Boushey CJ, Dawson-Hughes B, Lappe JM, LeBoff MS, Liu S, Looker AC, Wallace TC, Wang DD (2016) Calcium plus vitamin D supplementation and risk of fractures: an updated meta-analysis from the National Osteoporosis Foundation [published erratum and additional analyses appear in Osteoporos Int. 2016;27(8):2643-2646]. Osteoporos Int 27:367376. https://doi.org/10.1007/s00198-015-3386-5

5. (2015) Dietary Guidelines for Americans 2015-2020 US Department of Health and Human Services; U.S. Department of Agriculture, Washington, DC

6. Papaioannou A, Morin S, Cheung AM, Atkinson S, Brown JP, Feldman S, Hanley DA, Hodsman A, Jamal SA, Kaiser SM, Kvern B, Siminoski K, Leslie WD, for the Scientific Advisory Council of Osteoporosis Canada (2010) 2010 clinical practice guidelines for the diagnosis and management of osteoporosis in Canada: summary. CMAJ 182:1864-1873. https://doi.org/10. 1503/cmaj.100771

7. Cosman F, de Beur SJ, LeBoff MS, Lewiecki EM, Tanner B, Randall S, Lindsay R (2014) Clinician's guide to prevention and treatment of osteoporosis. Osteoporos Int 25:2359-2381. https:// doi.org/10.1007/s00198-014-2794-2

8. Hernlund E, Svedbom A, Ivergard M, Compston J, Cooper C, Stenmark J, McCloskey EV, Jonsson B, Kanis JA (2013) Osteoporosis in the European Union: medical management, epidemiology and economic burden. A report prepared in collaboration with the International Osteoporosis Foundation (IOF) and the European Federation of Pharmaceutical Industry Associations (EFPIA). Arch Osteoporos 8:136. https://doi.org/10.1007/s11657013-0136-1

9. Kanis JA, McCloskey EV, Johansson H, Cooper C, Rizzoli R, Reginster JY (2013) European guidance for the diagnosis and management of osteoporosis in postmenopausal women. Osteoporos Int 24:23-57. https://doi.org/10.1007/s00198-012-2074-y

10. (2016) Handout on health: osteoporosis. NIH Osteoporosis and Related Bone Diseases National Resource Center. https://www. niams.nih.gov/health_info/bone/osteoporosis/osteoporosis_hoh. asp. Accessed March 22, 2018

11. Blumberg JB, Frei BB, Fulgoni VL, Weaver CM, Zeisel SH (2017) Impact of frequency of multi-vitamin/multi-mineral supplement intake on nutritional adequacy and nutrient deficiencies in U.S. adults. Nutrients 9:1-15. https://doi.org/10.3390/nu9080849

12. Lips P, Hosking D, Lippuner K, Norquist JM, Wehren L, Maalouf G, Ragi-Eis S, Chandler J (2006) The prevalence of vitamin D inadequacy amongst women with osteoporosis: an international epidemiological investigation. J Intern Med 260:245-254. https:// doi.org/10.1111/j.1365-2796.2006.01685.x

13. Tai V, Leung W, Grey A, Reid IR, Bolland MJ (2015) Calcium intake and bone mineral density: systematic review and meta-analysis. BMJ 351:h4183. https://doi.org/10.1136/bmj.h4183

14. Bolland MJ, Leung W, Tai V, Bastin S, Gamble GD, Grey A, Reid IR (2015) Calcium intake and risk of fracture: systematic review. BMJ 351:h4580. https://doi.org/10.1136/bmj.h4580

15. Bischoff-Ferrari HA, Dawson-Hughes B, Baron JA, Kanis JA, Orav EJ, Staehelin HB, Kiel DP, Burckhardt P, Henschkowski J, Spiegelman D, Li R, Wong JB, Feskanich D, Willett WC (2011) Milk intake and risk of hip fracture in men and women: a metaanalysis of prospective cohort studies. J Bone Miner Res 26:833839. https://doi.org/10.1002/jbmr.279

16. Bischoff-Ferrari HA, Dawson-Hughes B, Baron JA, Burckhardt P, Li R, Spiegelman D, Specker B, Orav JE, Wong JB, Staehelin HB, O'Reilly E, Kiel DP, Willett WC (2007) Calcium intake and hip fracture risk in men and women: a meta-analysis of prospective cohort studies and randomized controlled trials. Am J Clin Nutr 86:1780-1790

17. (2018) Eurostat database. European Commission. http://ec.europa. eu/eurostat/data/database. Accessed February 21, 2018

18. (2018) Population. U.S. Census Bureau. https://www.census.gov/ topics/population.html. Accessed February 21, 2018

19. (2018) Population distribution by age. The Henry J. Kaiser Family Foundation. https://www.kff.org/other/state-indicator/distributionby-age $/$ ?currentTimeframe $=0 \&$ sortModel $=\% 7 \mathrm{~B} \% 22$ colId $\% 22: \%$ 22Location $\% 22, \% 22$ sort $\% 22: \% 22$ asc $\% 22 \% 7 \mathrm{D}$. Accessed February 21, 2018

20. Wright NC, Looker AC, Saag KG, Curtis JR, Delzell ES, Randall S, Dawson-Hughes B (2014) The recent prevalence of osteoporosis and low bone mass in the United States based on bone mineral density at the femoral neck or lumbar spine. J Bone Miner Res 29:2520-2526. https://doi.org/10.1002/jbmr.2269

21. Kanis JA, Oden A, McCloskey EV, Johansson H, Wahl DA, Cooper C (2012) A systematic review of hip fracture incidence and probability of fracture worldwide. Osteoporos Int 23:22392256. https://doi.org/10.1007/s00198-012-1964-3

22. Johnell O, Kanis JA (2006) An estimate of the worldwide prevalence and disability associated with osteoporotic fractures. Osteoporos Int 17:1726-1733. https://doi.org/10.1007/s00198006-0172-4

23. Burge R, Dawson-Hughes B, Solomon DH, Wong JB, King A, Tosteson A (2007) Incidence and economic burden of osteoporosis-related fractures in the United States, 2005-2025. J Bone Miner Res 22:465-475. https://doi.org/10.1359/jbmr.061113

24. Weycker D, Li X, Barron R, Bornheimer R, Chandler D (2016) Hospitalizations for osteoporosis-related fractures: economic costs and clinical outcomes. Bone Rep 5:186-191. https://doi.org/10. 1016/j.bonr.2016.07.005

25. (2018) Trends in health care spending. American Medical Association. https://www.ama-assn.org/about-us/trends-healthcare-spending. Accessed February 22, 2018

26. Chapuy MC, Arlot ME, Duboeuf F, Brun J, Crouzet B, Arnaud S, Delmas PD, Meunier PJ (1992) Vitamin D3 and calcium to prevent hip fractures in elderly women. N Engl J Med 327:1637-1642. https://doi.org/10.1056/nejm199212033272305 
27. Dawson-Hughes B, Harris SS, Krall EA, Dallal GE (1997) Effect of calcium and vitamin $\mathrm{D}$ supplementation on bone density in men and women 65 years of age or older. N Engl J Med 337:670-676. https://doi.org/10.1056/NEJM199709043371003

28. Porthouse J, Cockayne S, King C, Saxon L, Steele E, Aspray T, Baverstock M, Birks Y, Dumville J, Francis R, Iglesias C, Puffer S, Sutcliffe A, Watt I, Torgerson DJ (2005) Randomised controlled trial of calcium and supplementation with cholecalciferol (vitamin D3) for prevention of fractures in primary care. BMJ 330:1003. https://doi.org/10.1136/bmj.330.7498.1003

29. Prentice RL, Pettinger MB, Jackson RD, Wactawski-Wende J, LaCroix AZ, Anderson GL, Chlebowski RT, Manson JE, van Horn L, Vitolins MZ, Datta M, LeBlanc ES, Cauley JA, Rossouw JE (2013) Health risks and benefits from calcium and vitamin D supplementation: Women's Health Initiative clinical trial and cohort study. Osteoporos Int 24:567-580. https://doi.org/10.1007/s00198012-2224-2

30. Salovaara K, Tuppurainen M, Karkkainen M, Rikkonen T, Sandini L, Sirola J, Honkanen R, Alhava E, Kroger H (2010) Effect of vitamin $\mathrm{D}(3)$ and calcium on fracture risk in 65 - to 71 -year-old women: a population-based 3-year randomized, controlled trialthe OSTPRE-FPS. J Bone Miner Res 25:1487-1495. https://doi. org $/ 10.1002 / \mathrm{jbmr} .48$

31. Grant AM, Avenell A, Campbell MK et al (2005) Oral vitamin D3 and calcium for secondary prevention of low-trauma fractures in elderly people (randomised evaluation of calcium or vitamin D, RECORD): a randomised placebo-controlled trial. Lancet 365: 1621-1628. https://doi.org/10.1016/S0140-6736(05)63013-9

32. Harwood RH, Sahota O, Gaynor K, Masud T, Hosking DJ (2004) A randomised, controlled comparison of different calcium and vitamin D supplementation regimens in elderly women after hip fracture: the Nottingham Neck of Femur (NONOF) study. Age Ageing 33:45-51

33. Shanahan CJ, de Lorimier R (2016) From science to finance-a tool for deriving economic implications from the results of dietary supplement clinical studies. J Diet Suppl 13:16-34. https://doi.org/10. 3109/19390211.2014.952866

34. EFSA NDA Panel (2016) Scientific opinion on dietary reference values for vitamin D. EFSA J 14:4547. doi: https://doi.org/10.2903/ j.efsa.2016.4547

35. Hippisley-Cox J, Coupland C (2009) Predicting risk of osteoporotic fracture in men and women in England and Wales: prospective derivation and validation of QFractureScores. BMJ 339:b4229. https://doi.org/10.1136/bmj.b4229
36. Bischoff-Ferrari HA, Willett WC, Wong JB, Stuck AE, Staehelin HB, Orav EJ, Thoma A, Kiel DP, Henschkowski J (2009) Prevention of nonvertebral fractures with oral vitamin $\mathrm{D}$ and dose dependency: a meta-analysis of randomized controlled trials. Arch Intern Med 169:551-561. https://doi.org/10.1001/archinternmed. 2008.600

37. McCarron DA, Heaney RP (2004) Estimated healthcare savings associated with adequate dairy food intake. Am J Hypertens 17: 88-97

38. Zhao JG, Zeng XT, Wang J, Liu L (2017) Association between calcium or vitamin D supplementation and fracture incidence in community-dwelling older adults: a systematic review and metaanalysis. JAMA 318:2466-2482. https://doi.org/10.1001/jama. 2017.19344

39. Bolland MJ, Grey A, Avenell A (2018) Effects of vitamin D supplementation on musculoskeletal health: a systematic review, metaanalysis, and trial sequential analysis. Lancet Diabetes Endocrinol 6:847-858. https://doi.org/10.1016/s2213-8587(18)30265-1

40. Bischoff-Ferrari HA, Orav EJ, Abderhalden L, Dawson-Hughes B, Willett WC (2019) Vitamin D supplementation and musculoskeletal health. Lancet Diabetes Endocrinol 7:85. https://doi.org/10. $1016 / \mathrm{s} 2213-8587(18) 30347-4$

41. (2017) Council for Responsible Nutrition 2017 annual survey on dietary supplements. Council for Responsible Nutrition. https:// www.crnusa.org/resources/crn-2017-annual-survey-dietarysupplements. Accessed March 22, 2018

42. Bolland MJ, Avenell A, Grey A, Reid IR (2016) Errors in NOF meta-analyses of calcium and vitamin D supplements. Osteoporos Int 27:2637-2639. https://doi.org/10.1007/s00198-015-3466-6

43. Sornay-Rendu E, Munoz F, Garnero P, Duboeuf F, Delmas PD (2005) Identification of osteopenic women at high risk of fracture: the OFELY study. J Bone Miner Res 20:1813-1819. https://doi.org/ 10.1359/jbmr.050609

44. (2017) FRAX fracture risk assessment tool. University of Sheffield. https://www.sheffield.ac.uk/FRAX/. Accessed March 22, 2018

45. Oden A, McCloskey EV, Kanis JA, Harvey NC, Johansson H (2015) Burden of high fracture probability worldwide: secular increases 2010-2040. Osteoporos Int 26:2243-2248. https://doi.org/ $10.1007 / \mathrm{s} 00198-015-3154-6$

Publisher's note Springer Nature remains neutral with regard to jurisdictional claims in published maps and institutional affiliations. 